\title{
Microstructure and Wear Property of As-cast Mg-2-wt.\%-Sn Alloys after Different Heat Treatment Processes
}

\author{
Jung-Hsuan Chen, ${ }^{1}$ Yi-Fung Wang, ${ }^{2}$ Chuen-Guang Chao, ${ }^{2 *}$ and Tzeng-Feng Liu ${ }^{2}$ \\ ${ }^{1}$ Department of Industrial Education, National Taiwan Normal University, Taipei, Taiwan \\ ${ }^{2}$ Department of Materials Science and Engineering, National Chiao Tung University, Hsinchu, Taiwan
}

(Received July 6, 2018; accepted October 25, 2018)

Keywords: Mg-Sn alloy, microstructure, wear property, solution heat treatment

The developments of biodegradable materials for orthopaedic implants has been progressing rapidly for decades. Biodegradable implants can eliminate the need for a second surgery and avoid the possible risks of retained metallic implants, such as corrosion or strength weakening. Magnesium (Mg) alloy is one of the potential materials for biodegradable implants because of its good biocompatibility and biodegradability. In this study, the microstructures and mechanical properties, especially the wear behavior and friction characteristics of $\mathrm{Mg}-\mathrm{Sn}$ alloys, were investigated. $\mathrm{Mg}-\mathrm{Sn}$ alloys fabricated by the ingot casting method were applied to different heat treatments, and then subjected to the pin-on-disc wear test. Experimental results showed that the $\mathrm{Mg}-\mathrm{Sn}$ alloy processed by solution heat treatment (SHT) at $520{ }^{\circ} \mathrm{C}$ and quenching had the best wear resistance and lowest coefficient of friction (COF). The decrease in the amount of hard precipitate $\mathrm{Mg}_{2} \mathrm{Sn}$ and the solid-solution strengthening induced by the excess $\mathrm{Sn}$ atoms in the $\mathrm{Mg}$ matrix were the main causes of the enhancement of the wear properties of the $\mathrm{Mg}-\mathrm{Sn}$ alloy upon SHT, compared with as-cast $\mathrm{Mg}-\mathrm{Sn}$ alloy and the $\mathrm{Mg}-\mathrm{Sn}$ alloys made by other heat treatments.

\section{Introduction}

Orthopaedic implants can be divided into two groups: permanent implants, such as knee or hip prostheses, and temporary biodegradable implants such as screws and pins. ${ }^{(1-3)}$ Metals have mechanical properties similar to those of human bone compared with ceramics or polymers, and are commonly used as permanent implant materials, such as stainless-steel, titanium and cobalt-chromium alloys. ${ }^{(4)}$ With respect to biodegradable implants, magnesium alloys have been widely investigated for application to biological fields because of their good biocompatibility and biodegradability. Magnesium $(\mathrm{Mg})$ is also one of the important essential elements in the human body and is naturally stored in the bones. ${ }^{(5)}$ Additionally, $\mathrm{Mg}$ and its alloys could also be used as electrodes in biodegradable pressure sensors for cardiovascular monitoring or as RF components for wireless biosensor applications. ${ }^{(6,7)}$

For orthopedic implant applications, mechanical properties, biocorrosion characteristics, and cytotoxicity should be considered. The mechanical properties important in implant 
materials include yield strength, elastic modulus, tensile strength, elongation to breakage, and wear resistance. ${ }^{(8)}$ The components and composition of the Mg alloys contribute significantly to different mechanical properties and corrosion behaviors. Tin is often used as an alloying element to improve the mechanical properties and corrosion behavior of the Mg alloys. ${ }^{(9)}$ The cytotoxicities of the $\mathrm{Mg}-\mathrm{Sn}$ alloys were studied by Zhao and his coworkers. Their research revealed that no cell toxicity was induced in the $\mathrm{Mg}-\mathrm{Sn}$ alloys when the $\mathrm{Sn}$ content was less than 3 wt.\%. Alloys such as $\mathrm{Mg}-1-\mathrm{wt} . \%-\mathrm{Sn}$ and $\mathrm{Mg}-3-\mathrm{wt} . \%-\mathrm{Sn}$ alloys were suitable for use as biodegradable orthopedic implants. ${ }^{(10)}$ Additionally, many researchers have studied the mechanical properties and biocorrosion characteristics of the $\mathrm{Mg}-\mathrm{Sn}$ alloys. Cheng et al. investigated the mechanical properties of the extruded $\mathrm{Mg}-\mathrm{Sn}$ alloys with 6-10 wt.\% Sn and found that the tensile and compressive strengths increased with the Sn content while the yield asymmetry was the opposite. ${ }^{(11)}$ The effect of the grain refinement on the mechanical properties of $\mathrm{Mg}-\mathrm{Sn}$ alloys was evaluated by Dong et al. Their results showed that the ultimate tensile strength of the as-extruded alloy increased by $120 \%$ compared with that of as-cast alloys. ${ }^{(12)}$ Ha et al. investigated the effects of the volume fraction of the $\mathrm{Mg}_{2} \mathrm{Sn}$ intermetallic compounds, solutionized $\mathrm{Sn}$, and area fraction of grain boundaries on the corrosion properties of extruded alloys of $\mathrm{Mg}$ and 2-8 wt.\% Sn. They reported that the corrosion behavior primarily depended on the amount of $\mathrm{Mg}_{2} \mathrm{Sn}$. Moreover, when the area fraction of the grain boundaries increased, the $\mathrm{H}_{2}$ evolution rate was accelerated. ${ }^{(13)}$

However, very few studies focus on the wear behaviors of these Mg alloys. Furthermore, materials, especially metals and alloys, are often heat treated to improve their material properties. The mechanical characteristics are effectively controlled by appropriate heat treatments or thermal processes. In this study, $\mathrm{Mg}-2-\mathrm{wt} . \%-\mathrm{Sn}$ alloys with and without heat treatments were investigated to understand the wear mechanism and friction properties, as well as the consequences of these heat treatments.

\section{Materials and Methods}

In this study, Mg-2-wt.\%-Sn alloy was produced by the ingot casting method. Pure magnesium (99.95 wt.\%) and pure tin (99.98 wt.\%) were placed in a stainless-steel crucible and melted in a protective gas, $\mathrm{SF}_{6}$. The melt was heated to $800{ }^{\circ} \mathrm{C}$ and then poured into a steel mold with the dimensions of $300 \times 70 \times 60 \mathrm{~mm}^{3}$ at $720{ }^{\circ} \mathrm{C}$. The specimens for the wear test were machined into cylindrical pins of $8 \mathrm{~mm}$ diameter and $4 \mathrm{~mm}$ height by wire electrical discharge machining. Three processing heat treatments were applied to the machined $\mathrm{Mg}-\mathrm{Sn}$ alloy specimens. One was homogenization treatment $(\mathrm{HO})$ at $300{ }^{\circ} \mathrm{C}$ for $1 \mathrm{~h}$. Another was solution heat treatment (SHT) at $520^{\circ} \mathrm{C}$ for $15 \mathrm{~h}$ with cooling in a furnace (FC). The third was SHT at $520^{\circ} \mathrm{C}$ for $15 \mathrm{~h}$ followed by quenching in water. The microstructures and compositions of the as-cast (AC) and heat-treated $\mathrm{Mg}-\mathrm{Sn}$ alloy specimens were investigated by scanning electron microscopy (SEM, JEOL Tokyo, Japan) and energy-dispersive X-ray spectroscopy (EDS, Oxford Instruments Oxford, UK). The hardness was measured using the Vickers hardness test. The wear behavior and friction properties, such as friction coefficient and friction force, were evaluated by the pin-on-disc wear test. The wear test was operated without any lubricants using 
a conventional pin-on-disc testing machine (Plint Berkshire, England) at ambient temperature. The $\mathrm{Mg}-\mathrm{Sn}$ alloy was used as the pin and S45C steel with Rockwell $\mathrm{C}$ hardness (HRC) of approximately 50 was used as the disc-shaped counter-material. The track radius was $4 \mathrm{~mm}$ and the sliding velocity was maintained at $1.2 \mathrm{~m} / \mathrm{s}$. The load was $29.4 \mathrm{~N}$ over a distance of 2500 $\mathrm{m}$. The surfaces of the worn specimens and the wear debris were studied by SEM to clarify the wear mechanisms.

\section{Results and Discussion}

Figure 1 shows the microstructure of the $\mathrm{Mg}-\mathrm{Sn}$ alloys with and without heat treatment. In the as-cast $\mathrm{Mg}-\mathrm{Sn}$ alloy, the segregation phenomenon and the primary $\mathrm{Mg}$ dendrite were observed. Furthermore, an intermetallic compound, $\mathrm{Mg}_{2} \mathrm{Sn}$, formed mainly along the grain boundary. After the homogenization treatment at $300{ }^{\circ} \mathrm{C}$ for $1 \mathrm{~h}$, the solute $\mathrm{Sn}$ atoms precipitated in the form of $\mathrm{Mg}_{2} \mathrm{Sn}$ near the grain boundary. Therefore, the segregation was reduced and the amount of $\mathrm{Mg}_{2} \mathrm{Sn}$ increased after the homogenization treatment, as shown in Fig. 1(b). According to the Mg-Sn binary phase diagram, ${ }^{(14)} 520{ }^{\circ} \mathrm{C}$ was high enough to attain the single $\mathrm{Mg}$ phase. The equilibrium concentration of the $\mathrm{Sn}$ in the $\mathrm{Mg}$ matrix was greater than the total Sn content in the alloy; therefore, the $\mathrm{Mg}_{2} \mathrm{Sn}$ must have dissolved gradually if the

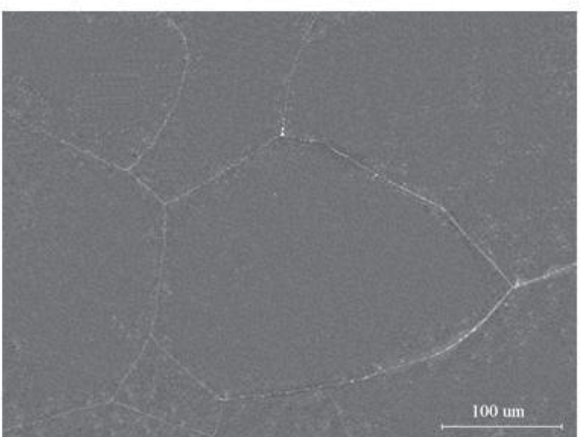

(a)

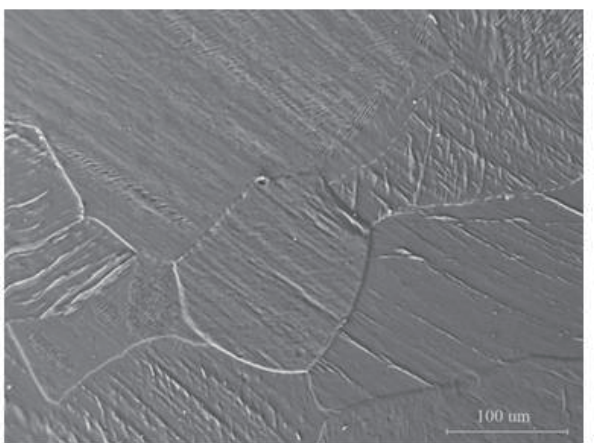

(c)

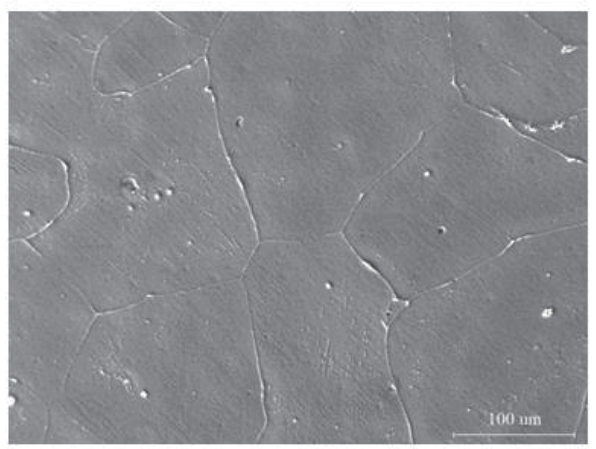

(b)

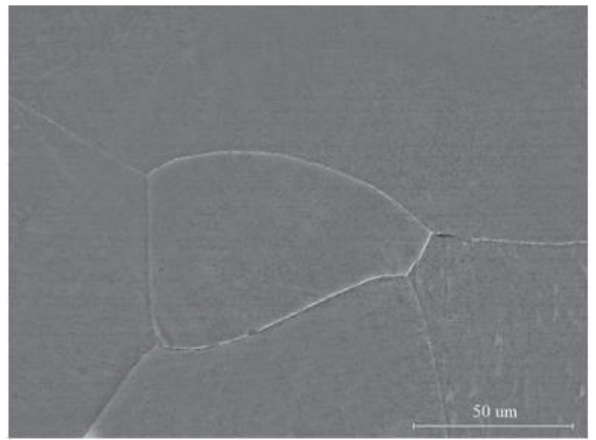

(d)

Fig. 1. Microstructures of Mg-Sn alloys: (a) AC, (b) HO, (C) FC, and (d) SHT. 
alloy was maintained for a sufficiently long time at an elevated temperature such as $520{ }^{\circ} \mathrm{C}$. Consequently, the Sn atom would be distributed uniformly in the $\mathrm{Mg}$ matrix after the heat treatment at $520{ }^{\circ} \mathrm{C}$ for $15 \mathrm{~h}$. Additionally, two different cooling methods were applied to the above alloys after they had been transformed into the homogeneous solid-state solutions at $520{ }^{\circ} \mathrm{C}$. During the cooling process, the alloy that was slightly unsaturated at the higher temperature would become extremely supersaturated. The precipitation of excess Sn atoms could be expected to occur spontaneously and the formation of $\mathrm{Mg}_{2} \mathrm{Sn}$ from a supersaturated solid solution may take place under a slow cooling condition such as the furnace cooling. Therefore, there was a small amount of $\mathrm{Mg}_{2} \mathrm{Sn}$ observed in the $\mathrm{FC}$ alloy, as shown in Fig. 1(c). Very rapid quenching, such as by water cooling, would prevent the appreciable diffusion of the Sn atoms, so it could be assumed that the solid solution that existed at $520{ }^{\circ} \mathrm{C}$ was cooled to room temperature essentially unchanged. The microstructure of the solution-heat-treated and quenched $\mathrm{Mg}-\mathrm{Sn}$ alloy is shown in Fig. 1(d). After the solution heat treatment and quenching process, not only the $\mathrm{Sn}$ atoms distributed uniformly in the $\mathrm{Mg}$ matrix but also the $\mathrm{Mg}_{2} \mathrm{Sn}$ precipitate completely disappeared.

The average grain size of the $\mathrm{Mg}-\mathrm{Sn}$ alloy was measured in the SEM image, and the results showed that the grain clearly grew when the thermal budget of the heat treatment increased. The average grain size was around $340 \mu \mathrm{m}$ after the alloy was heat-treated at $520^{\circ} \mathrm{C}$ for $15 \mathrm{~h}$, as presented in Fig. 2. However, the hardness was decreased after the homogenization treatment of the as-cast $\mathrm{Mg}-\mathrm{Sn}$ alloy, because a soft $\mathrm{Mg}$ matrix was produced after the precipitation of the $\mathrm{Sn}$ atoms during the homogenization treatment. Furthermore, the alloys subjected to the FC and SHT processes had higher hardness than the as-cast alloy owing to the formation of the supersaturated $\mathrm{Mg}$ phase in which the excess $\mathrm{Sn}$ atoms were dissolved. The major mechanism behind the increase in the strengths of the FC and SHT alloys was solid-solution strengthening.

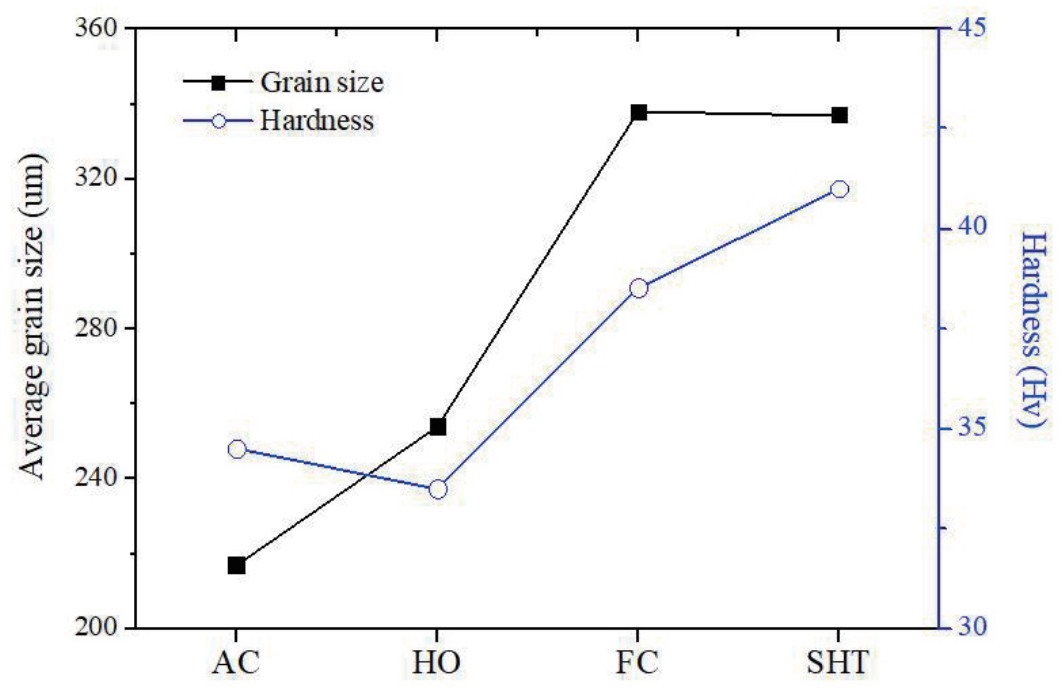

Fig. 2. (Color online) Average grain size and hardness of Mg-Sn alloys with and without heat treatment. 
The local stress fields and the distortion of the host structure occurred because of the existence of the extra $\mathrm{Sn}$ atoms in the $\mathrm{Mg}$ phase and made the dislocation movement more difficult, leading to an increase in the strength of the alloy. The amount of strengthening usually depended on the amount of the dissolved solute. This could explain why the SHT Mg-Sn alloy had a higher hardness than the FC alloy.

The wear behaviors of the $\mathrm{Mg}-\mathrm{Sn}$ alloys with and without heat treatments were investigated by pin-on-disc experiments. Figure 3 shows the hardness, wear resistance, and surface roughness of the worn surfaces of these $\mathrm{Mg}-\mathrm{Sn}$ alloys. The ranking of the hardness and the wear resistance was SHT alloy $>$ FC alloy $>$ AC alloy $>\mathrm{HO}$ alloy. The relationship between the hardness and the wear resistance could be explained by Archard's equation: ${ }^{(15)} W_{\text {Resistance }}=K H / N$. $K$ is the wear coefficient, $H$ is the hardness, and $N$ is the applied load during sliding. The wear resistance is linearly proportional to the hardness of the material under constant load. The wear resistance is enhanced when the hardness of the material increases. Although Archard's equation was developed for adhesive wear, it is widely used for modeling abrasive, fretting, and other types of wear. ${ }^{(16)}$ Additionally, the maximum wear resistance of $55.3 \mathrm{~m} / \mathrm{mm}^{3}$ was achieved in the SHT alloy in the present study. Regarding the roughness of the worn surface, a rough surface could be observed for the alloy with poor wear resistance.

Worn surface damage features and wear debris were examined most often when discussing the wear mechanism or the wear mode. The worn surface morphologies of the $\mathrm{Mg}-\mathrm{Sn}$ alloys were inspected by SEM. As seen in Fig. 4, there were scratches and grooves due to abrasive

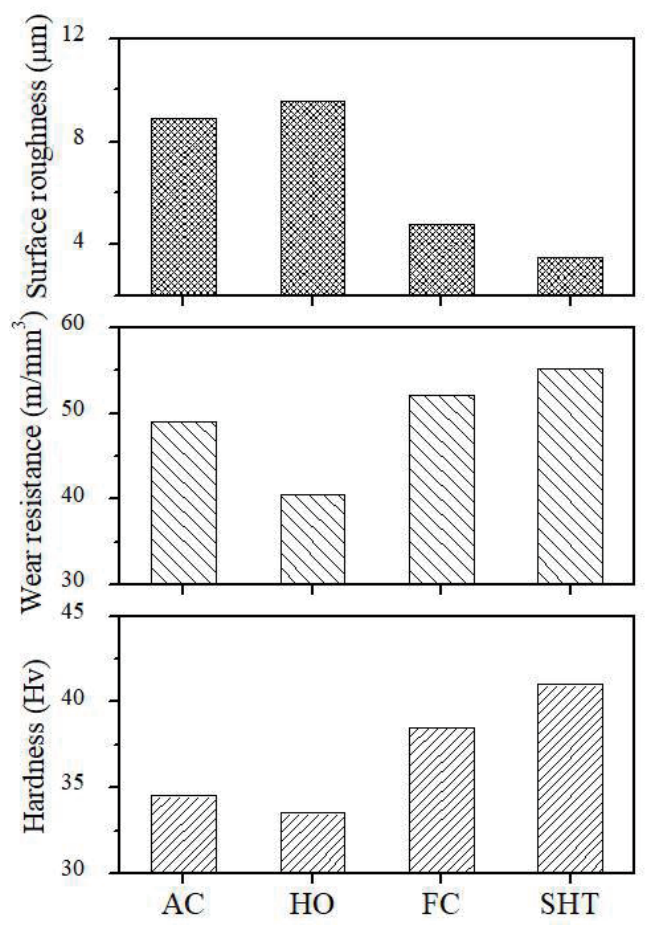

Fig. 3. Hardness, wear resistance, and surface roughness of the worn surface of the Mg-Sn alloys with and without heat treatment. 


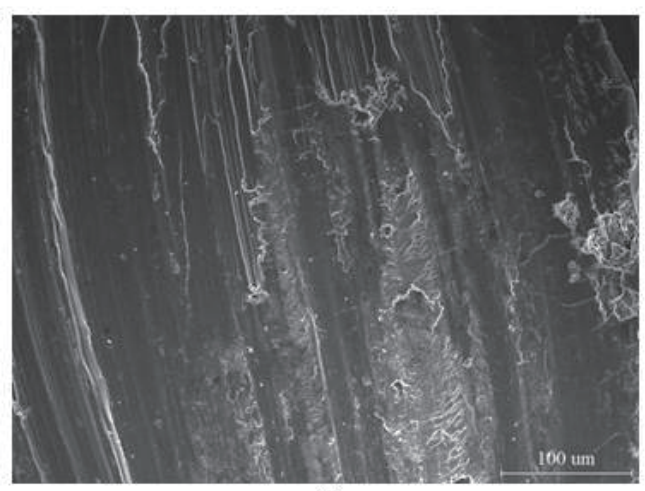

(a)

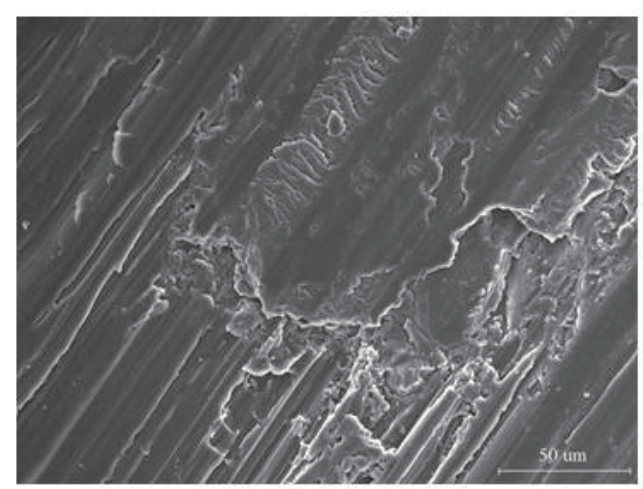

(c)

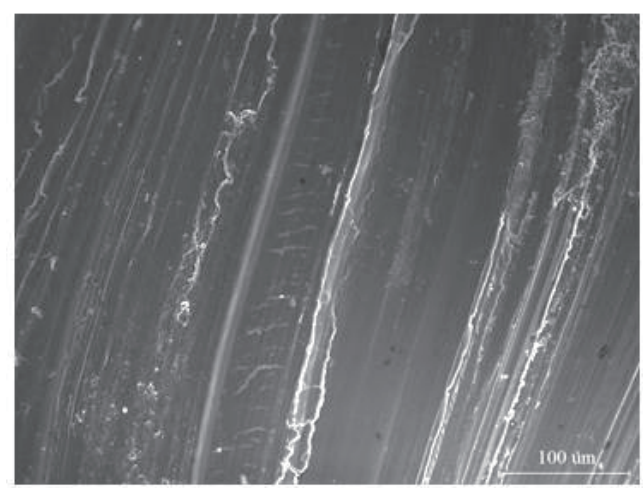

(e)

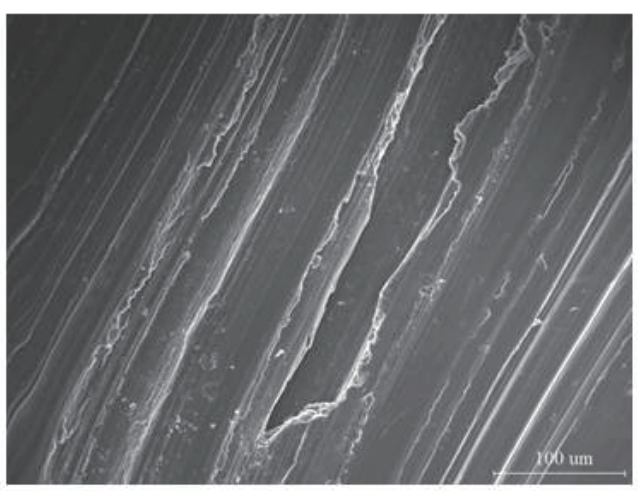

(b)

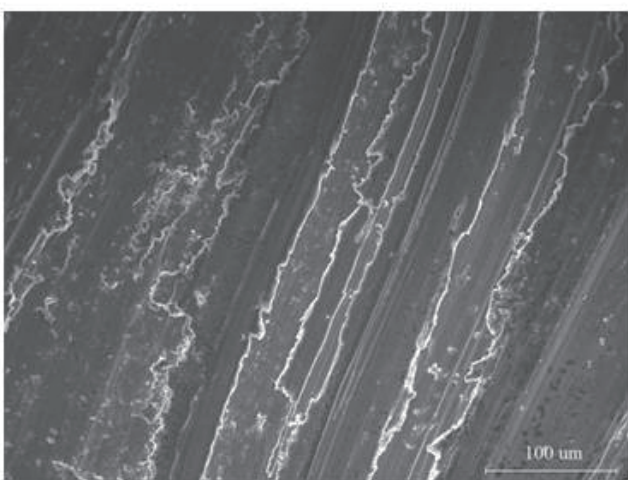

(d)

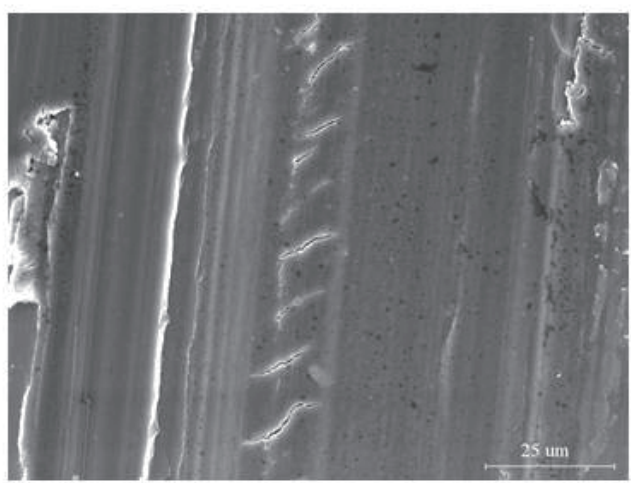

(f)

Fig. 4. Worn surface morphologies of the Mg-Sn alloys after the pin-on-disc wear test: (a) AC; (b) and (c) HO; (d) FC; (e) and (f) SHT.

wear on the worn surfaces of the $\mathrm{AC}$ alloy and the $\mathrm{HO}$ alloy. Moreover, transferred layers or lumps and plowing with plastic deformation caused by the adhesive wear were also observed in the AC and HO alloys. After SHT, the amount of transferred lump owing to adhesion decreased and abrasive damage such as microcracks and scratches was mainly observed on the worn surface, as seen in Figs. 4(e) and 4(f). SHT was an effective way of reducing the precipitation of $\mathrm{Mg}_{2} \mathrm{Sn}$, which acts as asperities or wear particles, and enhancing the hardness of material. Therefore, the SHT alloy had the maximum wear resistance among all specimens. 
Figure 5 shows SEM morphologies of wear debris. The shape and size of the wear debris were also used to describe the wear mechanisms. ${ }^{(17-19)}$ Wear debris or wear particles are usually the products of surface damage, friction transfer, and final material removal by sliding. The wear debris collected from the AC and HO alloys was of several types: platelets and flakes, curls, and microcutting chips. Such wear debris is produced by the combined effects of adhesion and abrasion. The number of large platelets and flakes is clearly reduced in the FC and SHT alloys because the improved hardness of the contacting material reduces the possibility of adhesion between contacting surfaces. As a result, the amount of wear debris originating from the transferred fragments with platelike morphology would decrease. Moreover, a decreasing trend of the wear debris quantity was observed because hard materials undergo less wear than soft materials under the same friction conditions. ${ }^{(20)}$

The friction properties of the $\mathrm{Mg}-\mathrm{Sn}$ alloys with and without heat treatment were also discussed in this study. Friction is the resistance to sliding motion along an interface and the coefficient of friction (COF) describes the ratio of frictional force to normal force. The COF in sliding depends on the materials that cause friction between moving surfaces and is often symbolized as $\mu_{k}$, the coefficient of kinetic friction. A value of zero means no friction between the objects. Figure 6 shows that the SHT alloy had the best COF, 0.02, while the HO alloy had the COF of 0.21 . The friction coefficient tended to be high because there were many hard precipitates of $\mathrm{Mg}_{2} \mathrm{Sn}$ acting as asperities on the surface of the $\mathrm{HO}$ alloy.

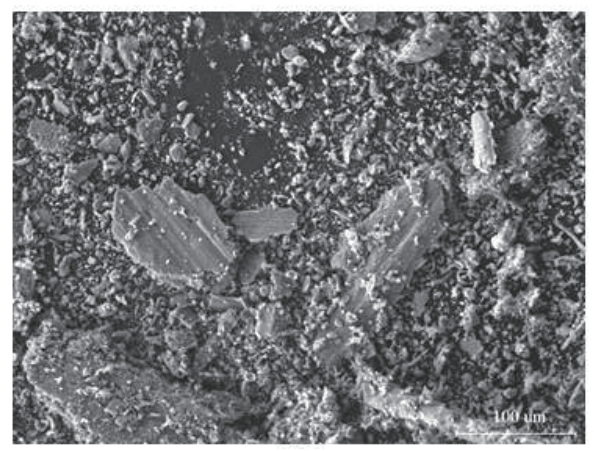

(a)

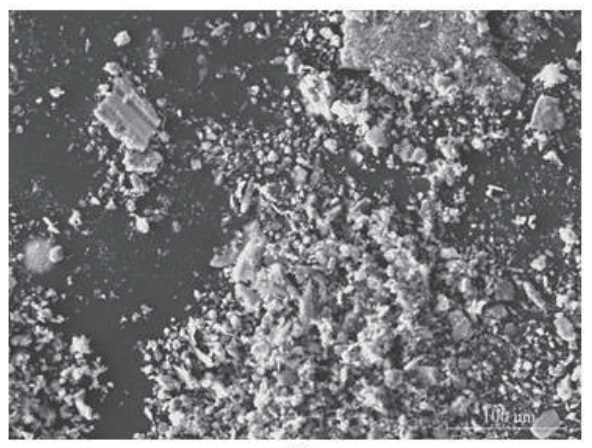

(c)

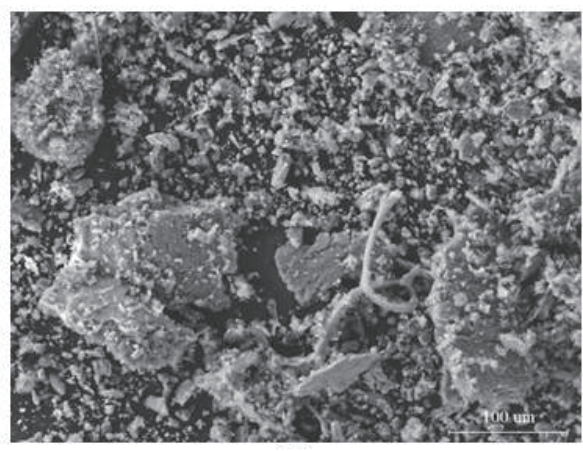

(b)

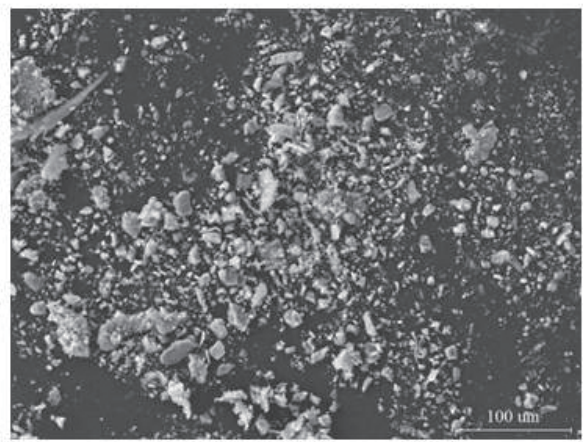

(d)

Fig. 5. Morphologies of wear debris: (a) AC, (b) HO, (c) FC, and (d) SHT. 


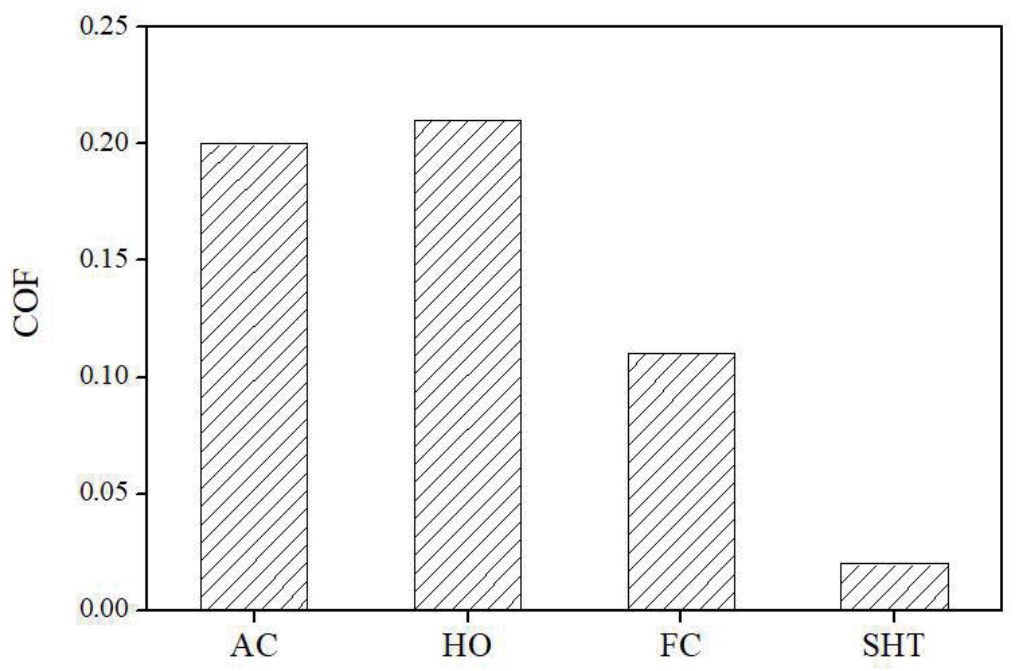

Fig. 6. $\mathrm{COF}$ of the $\mathrm{Mg}-\mathrm{Sn}$ alloys with and without heat treatment.

\section{Conclusions}

Mg-2-wt.\%-Sn alloy was fabricated by the ingot casting method in this study. Because the mechanical properties may be altered significantly if the alloy is subsequently heated, we investigated the effect of heat treatment on the wear properties of the Mg-2 wt.\% Sn alloy. There were three different heat treatment processes (HO, FC, and SHT) used in this work. The experimental results showed the following. The wear resistances of the $\mathrm{Mg}-\mathrm{Sn}$ alloys were enhanced after the FC and SHT treatments. Moreover, the trend in the wear properties of the $\mathrm{Mg}-\mathrm{Sn}$ alloys corresponded to that in the hardness of the $\mathrm{Mg}-\mathrm{Sn}$ alloys. The COF of the $\mathrm{Mg}-\mathrm{Sn}$ alloys decreased as follows: $\mathrm{HO}>\mathrm{AC}>\mathrm{FC}>\mathrm{SHT}$. This indicated that the existence of $\mathrm{Mg}_{2} \mathrm{Sn}$ causes unevenness of and damage to the surface during the wear test, and the rougher surface tended to result in a higher friction coefficient. Furthermore, the best wear resistance of $55 \mathrm{~m} / \mathrm{mm}^{3}$ was obtained from the Mg-Sn alloy with SHT, and this alloy also had the lowest worn surface roughness and COF of 0.02 .

\section{Acknowledgments}

The authors gratefully acknowledge the support of the Ministry of Science and Technology of the Republic of China through Grant Nos. MOST106-2218-E-003-002 and 107-2622-E-003004-CC3.

\section{Conflicts of Interest}

The authors declare no potential conflicts of interest with respect to the research, authorship, and publication of this article. 


\section{References}

1 S. Agarwal, J. Curtin, B. Duffy, and S. Jaiswal: Mater. Sci. Eng., C 68 (2016) 948.

2 D. da Silva, M. Kaduri, M. Poley, O. Adir, N. Krinsky, J. Shainsky-Roitman, and A.Schroeder: Chem. Eng. J. 340 (2018) 9.

3 A. R. Amini, J. S. Wallace, and S. P. Nukavarapu: J. Long Term Eff. Med. Implants 21 (2011) 93.

4 N. Liand and Y. Zheng: J. Mater. Sci. Technol. 29 (2013) 489.

5 J. Walker, S. Shadanbaz, T. B. Woodfield, M. P. Staiger, and G. J. Dias: J. Biomed. Mater. Res. Part B 102 (2014) 1316.

6 C. M. Boutry, A. Nguyen, Q. O. Lawal, A. Chortos, S. Rondeau-Gagné, and Z. Bao: Adv. Mater. 27 (2015) 6954.

7 M. Luo, A. W. Martinez, C. Song, F. Herrault, and M. G. Allen: J. Microelectromech. Syst. 23 (2014) 4.

8 R. Radhaand and D. Sreekanth: J. Magnesium Alloys 5 (2017) 286.

9 J. Kubásek, D. Vojtěch, J. Lipov, and T. Ruml: Mater. Sci. Eng., C 33 (2013) 2421.

10 C. Zhao, F. Pan, S. Zhao, H. Pan, K. Song, and A. Tang: Mater. Des. 70 (2015) 60.

11 W. L. Cheng, S. S. Park, B. S. You, and B. H. Koo: Mater. Sci. Eng., A 527 (2010) 4650.

12 C. Dong, Y. P. Ren, G. Yun, W. L. Pei, H. D. Zhao, and G. W. Qin: Trans. Nonferrous Metals Soc. China 20 (2010) 1321.

13 H. Y. Ha, J. Y. Kang, S. G. Kim, B. Kim, S. S. Park, C. D. Yim, and B. S. You: Corros. Sci. 82 (2014) 369.

14 T. B. Massalski, J. L. Murray, L. H. Bennett, and H. Baker: Binary Alloy Phase Diagrams. in Volume 2; American Society for Metals (Metals Park, Ohio, 1986) p. 1547.

15 J. H. Chen, Y. C. Shen, C. G. Chao, and T. F. Liu: Materials 10 (2017) 1315.

16 A. B. Aghdamand and M. M. Khonsari: Wear 270 (2011) 781.

17 N. K. Myshkin and L. V. Markova: On-line Condition Monitoring in Industrial Lubrication and Tribology (Springer, Cham, Switzerland, 2018) p. 131.

18 M. A. Khan and A. G. Starr: Insight: Non-Destr. Test. Condition Monit. 48 (2006) 470.

19 W. A. Glaeser: Modern Tribology Handbook (CRC Press, Boca Raton, Florida, 2000) p. 301.

20 K. Kato: Wear 241 (2000) 151. 